\title{
Health Seeking Behaviour of Pregnant Women in South East of Nigeria: Implication for Improved Natal and Postnatal Care
}

\author{
Osuala E. $0^{1}$, Ezenduka P. 01, Nwankwo C. U1, Okafor CN1, \\ Odira Chika1
}

${ }^{1}$ Department of Nursing Science, Nnamdi Azikiwe University, Nnewi Campus, South East, Nigeria

\begin{abstract}
This study examined the choice of place of care by expectant mothers in a Local Government in Anambra State and factors that influence such choices in order to identify factors that militate against health -seeking behavior among the group and proffer solution. The study population was 82 pregnant women in a Primary Health Center in the State. Purposive sampling technique was adopted in the selection of the respondents. Three research questions and four null hypotheses guided the study. The instrument used for data collection was structured questionnaire. Face and content validity of tool was ascertained by Experts while correlation coefficient of 0.83 was established through a pilot study. Demographic information was also obtained for the study. With SPSS version 20, descriptive analysis was done to answer the research questions while Chi-square test was adopted in testing the null hypotheses at 0.05 level of significance. The result showed that the choice of place of care had significant correlation with level of education $(\mathrm{r}=0.306, \mathrm{p}<0.05)$ and parity $(\mathrm{r}=-0.283, \mathrm{p}<0.05)$ However it had no significant relationship with age $(\mathrm{r}=0.084, \mathrm{p}>0.05)$ and income $(\mathrm{r}=0.207, \mathrm{p}>0.05)$ of the respondents. This calls for free education programme for women by the Government to boost educational level among the group as well as organized programme for adolescent girls on the importance of health - seeking behavior in pregnancy.
\end{abstract}

Keywords: Expectant-mothers, Knowledge, Health-Behaviour, Midwifery-services

\section{Introduction}

For a positive outcome of pregnancy which aims at having a live mother and child, early registration of expectant mothers at an institution where there are skilled midwives is an imperative. This is termed Antenatal Care. The World Health Organization (WHO) defined antenatal care as a specialized pattern of care organized for pregnant women to enable them attain and maintain a state of good health throughout pregnancy and to improve their chances of having safe delivery of healthy infants at term, and a healthy mother after delivery (WHO, 2006). The services of the midwives can only be accessed on contact. Despite efforts put in place by the Ministry of Health at the three tiers Government to reduce maternal morbidity and mortality, low patronage by pregnant women has been observed by researchers hence the need to investigate the choice of pregnant women in respect of where care is accessed and factors that influence such choice. Pregnant women ideally seek care from trained and skilled Midwives for positive outcome of pregnancy with maternal and child health as the bottom-line. Maternal health refers to the health of women during pregnancy, childbirth and post partum period. It encompasses the health care dimensions of family planning, preconception, prenatal and postnatal care in order to reduce morbidity and mortality (WHO, 2005). Basavanthappa, (2008) contributes that maternal and child health refers to promotive, preventive, curative and rehabilitative health care activities for mothers and children, the aim of which includes reduction of maternal, infant and childhood morbidity and mortality; to promote reproductive health, physical and psychological development of children and adolescents. Efforts have been made by Government and Non Governmental Agencies to achieve this goal through provision of facilities and personnel, being guided by Primary Health Care principles.

Some approved Government health establishments in Nigeria, train midwives who are registered on qualification by the regulatory agency (Nursing \& Midwifery Council of Nigeria). These Midwives are

This article is published under the terms of the Creative Commons Attribution License 4.0

Author(s) retain the copyright of this article. Publication rights with Alkhaer Publications.

Published at: http://www.ijsciences.com/pub/issue/2017-04/

DOI: 10.18483/ijSci.1238; Online ISSN: 2305-3925; Print ISSN: 2410-4477 
distributed through the three tier of Government to provide quality midwifery services to its women. In order to boost their services, the Community Health Extension Workers (CHEWs) and the Midwives Services Scheme (MSS) were introduced. MSS is the Federal Government of Nigeria's intervention to reverse the poor maternal and health outcomes in Nigeria based on the memorandum by nursing leaders. The Scheme was introduced by the Federal Government of Nigeria under the appropriation Bill of 2009 to act as quick intervention to reduce the abnormally high death rates of women due to pregnancy related causes and children in Nigeria and facilitate the attainment of MDGs 4 and 5 (N\&MCN, 2011). In recognition that reduction of maternal mortality rate is a key Millennium Development Goal (MDGs) (MDGs, 2014), the Nursing and Midwifery Council of Nigeria (N\&MCN) established the Midwifery Services Scheme progamme (MSS) to overcome the shortage of skilled midwives in rural communities in order to achieve the $4^{\text {th }} \& 5^{\text {th }}$ MGDs. Despite efforts geared towards maternal health, maternal mortality and morbidity still pose a problem in Nigeria as it is stated to contribute almost $10 \%$ of world's maternal deaths (FMOH, 2005). Although maternity coverage is high in some countries, there still exists gap in the continued use of maternity care, especially utilization of skilled assistance during delivery. Finding in Bangladesh showed that a community based evidence on obstetric complications and maternal care seeking behavior remains limited in low resource Countries (Michael, Koenig, Jamil, Streatfield, Saha, Al-Sabir, Arifeen \& Yasmin, 2007). Could the prevalence of maternal mortality and morbidity in Nigeria be inherent on health seeking behavior of pregnant women? If it is what are the causes and remedies as no life need be lost to childbirth.

\section{Method}

The study is a descriptive survey of non experimental design that took place at a Primary Health Center (PHC) of a Local Government Area in the South East of Nigeria. The target population was the pregnant and puerperal women that attended the facility in February 2014. Only the pregnant women that voluntarily consented were included in the study. With purposive sampling method a total of 82 participants were drawn on two consecutive visits by the researchers. Instrument was structured questionnaire, constructed to draw out responses appropriate to the objectives of the study. The questionnaire was in sections that addressed the demographic data of the respondents, their knowledge and attitude towards antenatal care as well as information on choice of health care facility and its determinants. Face and content validity of tool was carried out by Experts. Pilot test was done and Correlation coefficient computed (0.83). Data was collected through the register and self administration of questionnaire after obtaining ethical approval from the Head of the PHC and each respondent. A total of 82 questionnaires were distributed with $100 \%$ return. Descriptive and inferential analysis was done using SPPS version 20 at a significant level of 0.05 . Relationship between demographic variables and knowledge as well as choice of place of care was computed. Result was presented in summaries, tables and graphs.

\section{Results}

Demographic: Age of respondents ranged from 2055, mean 34.5 and SD 8 .4. Parity ranged from 1-8 with a mean of 3 and SD 1.7. $70(85.4 \%)$ of the respondents are married and the rest. 12(14.6\%) are single. $42(51.2 \%)$ of the respondents are between the ages of $20-34$ and $40(47.8 \%)$ for ages $35-49$. $20(24.4 \%)$ of the participants are Anglican while $50(61 \%)$ are Catholic and the rest $12(14.6 \%)$ are Pentecostal Christians. There was no Muslim. $3(3.7 \%)$ of respondents are fully complete house wives while $5(6.1 \%)$ are civil/public servants and the rest $74(90.2 \%)$ are skilled/artisan. $36(43.9 \%)$ of the respondents earn less than $\mathrm{N} 500$ per day while $27(32.9 \%)$ do make between $\mathrm{N} 500$ to N1000 per day and the rest $19(23.2 \%)$ do make more than $\$ 1000$ per day respectively. Out of 82 participants in the study $56(68.3 \%)$ have one wife, $16(19.5 \%)$ have two wives while $5(6.1 \%)$ each have three and four wives respectively.

\section{Knowledge of pregnancy Associated Problems:}

The problems associated with pregnancy according to the respondents are as follows: 50(61\%) indicated bleeding, 11(13.4\%) indicated morning sickness while $9(11 \%)$ stated fainting attacks. 6(7.3\%) dyspepsia and constipation were stated by $6(7 \%)$ each.

Relationship between Knowledge of Pregnancy and Age, Level of Education, Income and Parity showed that knowledge of pregnancy had significant correlation with level of education $(r=0.225$, $\mathrm{p}<0.05)$. However it had no significant relationship with age $(\mathrm{r}=-0.025, \mathrm{p}>0.05)$, income $(\mathrm{r}=0.009, \mathrm{p}$ $>0.05)$ and parity $(\mathrm{r}=-0.010, \mathrm{p}>0.05)$ of the respondents.

\section{Attitude:}

Opinions of respondents on choice of place of care and motivating factors were sought. 


\section{Motivating factors:}

Factors that will influence ANC attendance according to respondents were as follows: $12(14.6 \%)$ and $27(32.9 \%)$ of the respondents attend antenatal care where services are free or at a low cost respectively while positive attitude of personnel is $13(15.9 \%)$ and high patronage is $12(14.6 \%)$. The rest $3(3.7 \%)$ will attend if "big people" are attending. Outcome of pregnancy also informed their decision. $43(52.4 \%)$ is of opinion that pregnancy is safer in government hospitals, $28(34.1 \%)$ is of opinion that pregnancy is safer in mission hospital, $7(8.5 \%)$ agree that it safer in private hospital while $3(3.7 \%)$ agree that pregnancy is safer in maternities and the $1(1.2 \%)$ agree that pregnancy is safer in faith clinic. In their opinion government health establishment would have been the preferred choice of many if not for perceived barriers.

\section{Choice of place of care:}

$16(19.5 \%)$ of the respondents prefer primary health centre, 24(29.3\%) prefer Mission Hospital, $11(13.4 \%)$ prefer General Hospital while 23(28\%) prefer teaching Hospital and $8(9.8 \%)$ prefer private hospital. Decision on choice of place of care is driven by cost $5(6.1 \%)$ accessibility, 12(14.6\%), attitude of health workers $25(30.5 \%)$ while quality of care $34(41.5 \%)$ and availability of equipment and materials in the facility $6(7.3 \%) .21(25.6 \%)$ of the respondents registered their pregnancy when it was less than three months, 3 to 5 months: $47(57.3 \%)$ while 5 to 7 months :7(8.5\%) and 7 months and above $7(8.5 \%)$.

Relationship between Choice of Care of Pregnancy and Age, Level of Education, Income and Parity showed that the choice of place of care had significant correlation with level of education $(\mathrm{r}=$ $0.306, p<0.05)$ and parity $(r=-0.283, p<0.05)$ However it had no significant relationship with age $(\mathrm{r}$ $=0.084, p>0.05)$ and income $(r=0.207, p>0.05)$ of the respondents.

\section{Discussion}

Findings of this study was similar to that carried out in Bangladesh showed in which health seeking behavior remains limited (Michael, et al, 2007). Booking at the PHC was however done early by most of the participants who visited the complex. Majority stated that their choice of a facility is influenced by quality of care and attitude of health personnel. Attitude of husbands and the health workers ranked highest among the barriers to health facility patronage. In the region where the study was undertaken, based on culture and religion men are the head of each family and takes most decisions on behalf of the women. Since husbands not involved in Antenatal visits, this could have been reason for the barrier. Absence of the health workers and negative attitude of those in attendance was another issue. This could be frustrating, more so to a pregnant woman due to the physiological changes. Clients visit health facilities in order to receive attention and care from health workers. Antenatal care is paramount in positive outcome of pregnancy and need to be encouraged through prompt attention and excellent practice by health professional, especially the midwives.

\section{Conclusion}

Level of education had a significant relationship with choice of place of care as well as knowledge of problems associated with pregnancy. Girl -Child education should be encouraged as well as women empowerment so that women would have a right to make a choice of care when pregnant. Awareness on benefits of antenatal care should be created through seminars for married couples. The findings of this study however can not be generalized because of the scope and population size. Further study with a larger population is therefore being recommended. Nevertheless, Health seeking behavior by mothers is a basic step in reduction of maternal and child morbidity cum mortality in our society and should therefore be the focus of every nurse/ midwife in Nigeria.

\section{References}

I. World Health Organization, "Reproductive Health Indicator Guidelines for their Generation, Interpretation and Analysis for Global Monitoring": WHO Geneva, 2006; 531p

II. WHO, "Maternal and Reproductive Health"2005. Retrieved 3 February, 2015 from http://www.who.int/gho/maternal_health/en/index.html

III. B.T. Basavanthappa, "Community health Nursing", 2008. New Delhi: Jaypee brothers medical publishers (p) LTD.

IV. Nursing and Midwifery Council of Nigeria "Midwifery Services Scheme" News letter July 2011 Ed 14 (7):35

V. Millennium Development Goal (MGDs). Retrieved on June 23, 2014 from http://www.unmillenniumoproject.org/htm/dev.goals.sh tm.

VI. Federal Ministry of Health, Nigeria. "Roadmap for accelerating the attainment of the millennium development goals related to maternal and newborn health in Nigeria". FMOH Abuja, Nigeria; 2005

VII. A.Michael, K. Koenig, P.K. Jamil, T. Streatfield, A. Saha, S. Al-Sabir, K. Arifeen, and H. Yasmin, H. "Maternal health and care seeking behavior in Bangladash: finding from a National survey" 2007. Retrieved 3 Febuary, 2015 from www.guttmacher.org/pub/journals/3307507.pdf. 


\section{Table 1: Demographic Characteristics of Respondents $\quad n=82$}

\begin{tabular}{|c|c|c|c|}
\hline & & Frequency & Percent (\%) \\
\hline \multirow[t]{8}{*}{ Age } & $20-20 \mathrm{YRS}$ & & \\
\hline & $20-291 \pi 0$ & 30 & 36.6 \\
\hline & $30-39$ YRS & 34 & 41.5 \\
\hline & $40-49$ YRS & 15 & 18.3 \\
\hline & $50-59$ YRS & 2 & 2.4 \\
\hline & & 1 & 1.2 \\
\hline & $>59$ YRS & 82 & 100.0 \\
\hline & Total & & \\
\hline \multirow[t]{4}{*}{ Marital Status } & Married & & \\
\hline & Single & 70 & 85.4 \\
\hline & Singie & 12 & 14.6 \\
\hline & Total & 82 & 100.0 \\
\hline
\end{tabular}

\section{Parity}

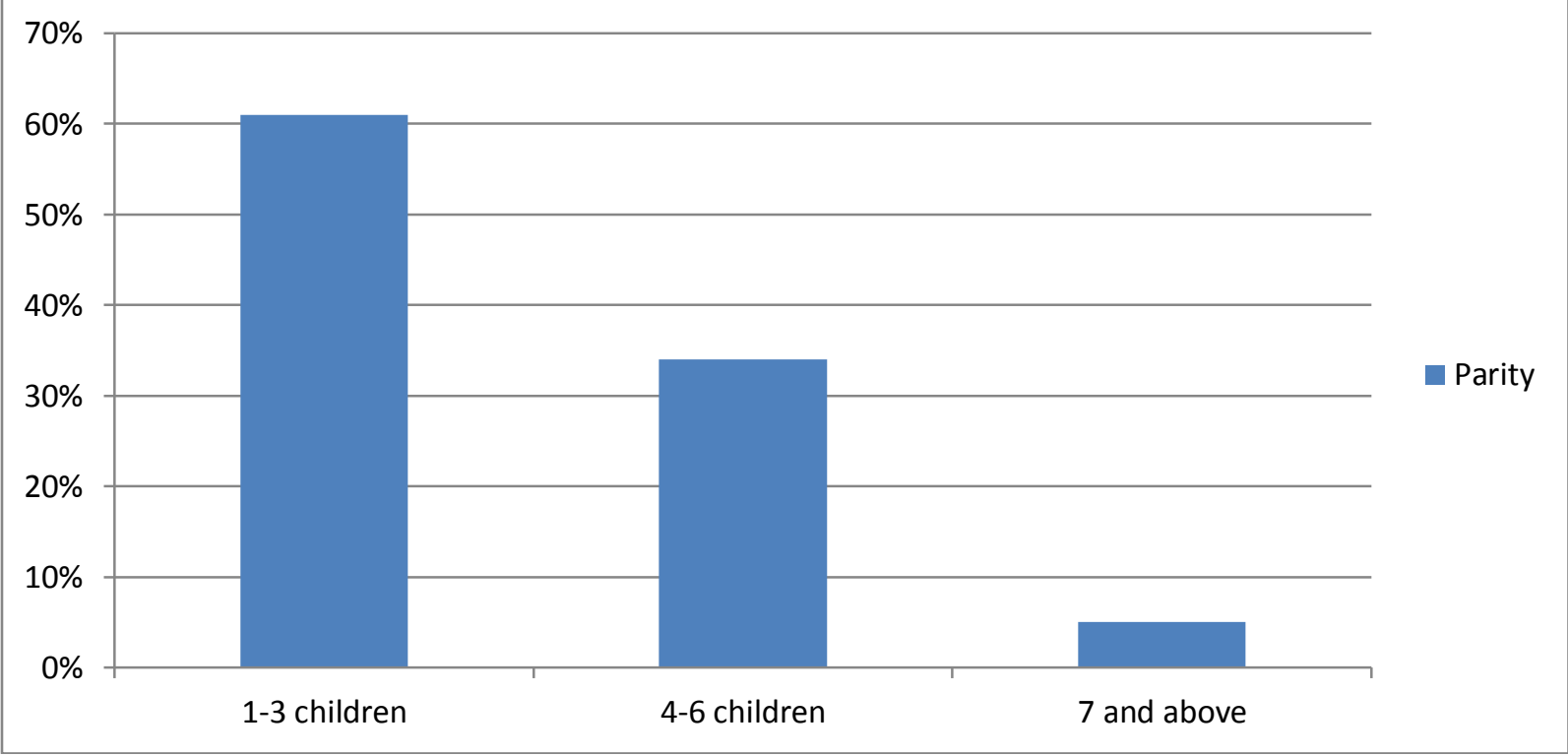

Fig 1: Parity of Respondents 


\section{Educational status}

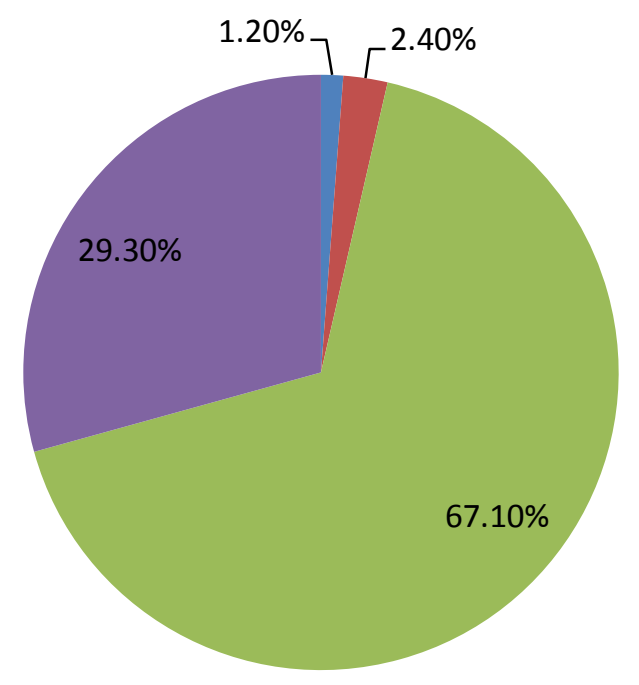

Non formal

- Primary

Secondary

- Tertiary

Fig 2: Educational levels of respondents.

Table1: Frequency counts showing opinion of respondents on factors that will make them attend antenatal care Clinics

\begin{tabular}{|l|r|r|}
\hline Statement & Frequency & Percent \\
\hline Services are free & 12 & 14.6 \\
Cost is low & 27 & 32.9 \\
Big people are attending & 3 & 3.7 \\
Personnel respects you & 27 & 32.9 \\
Patronage is high & 13 & 15.9 \\
Total & 82 & 100.0 \\
\hline
\end{tabular}

Table 2: Frequency counts showing the opinion of pregnant women on choice of place of care:

\begin{tabular}{|l|r|r|}
\hline Places of care & Frequency & Percent \\
\hline Government Hospitals & 43 & 52.4 \\
Private Hospital & 7 & 8.5 \\
Mission Hospitals & 28 & 34.1 \\
Faith Clinic (Prayer House) & 1 & 1.2 \\
Maternities & 3 & 3.7 \\
Total & 82 & 100.0 \\
\hline
\end{tabular}

